\title{
Use of TLR9 and TLR7/8 Agonists in Combination With D-Galactosamine in Exploring Models for Distinct Severities of Systemic Inflammation Relative To Liver Injury
}

\author{
Reiko SEKI $^{1}$, Kazuhisa NISHIZAWA ${ }^{1}$ \\ ${ }^{1}$ Department of Clinical Laboratory Science, Faculty of Medical Technology, Teikyo University, \\ Tokyo, Japan
}

Received February 26, 2020

Accepted October 13, 2020

Epub Ahead of Print November 19, 2020

\begin{abstract}
Summary
Challenges with various TLR ligands (TLRLs) in combination with D-galactosamine (GalN) in rodents may mimic diverse conditions of acute inflammation and organ failure. Here, we report that $\mathrm{CpG}$ (ODN1826, TLR9 agonist)/GalN induced a liver-specific injury with modest systemic effects, whereas R848 (resiquimod, TLR7/8 agonist)/GalN exhibited systemic and liver toxicity. We also observed the protective effect of $\mathrm{Gr}^{-} 1^{+}$cells (the population containing neutrophils) against liver injury in both the R848/GalN and $\mathrm{CpG} / \mathrm{GalN}$ models. In cytokine measurements, the intraperitoneal administration of antibodies showed a non-specific tolerance induction effect, which was more pronounced in the $\mathrm{CpG} / \mathrm{GaIN}$ than in the R848/GalN model. Cytokine analyses also suggested that the TLR9 agonist/GalN induced a limited degree of systemic inflammation compared to TLR7/8 agonist/GalN models. The relevance of this finding to the TLR9-mediated induction of stress tolerance (protective effect) in non-immune cells is discussed.
\end{abstract}

\section{Key words}

IL-6/IL-10 • Liver injury • Endotoxin tolerance • LPS • Intravenous immunoglobulin therapy

\section{Corresponding author}

Reiko Seki, Department of Clinical Laboratory Science, Faculty of Medical Technology, Teikyo University, Kaga 2-11-1, Itabashi ward, Tokyo, Japan 173-8605. E-mail: hyk@med.teikyo-u.ac.jp

\section{Introduction}

Administration of lipopolysaccharide (LPS) in combination with GalN is a widely studied model for acute liver failure and inflammation-mediated organ injury (e.g., Kemelo et al. 2017). GalN can impede uridine metabolism, possibly inducing cell stress. Various TLR ligands (TLRLs) in combination with GalN can induce liver injury (Seki 2017). Both TLR7/8 and TLR9 are endosomal receptors, but in our experiments, R848/GalN induced more severe signs of illness as compared to $\mathrm{CpG} / \mathrm{GalN}$, despite the use of the doses inducing similar levels of liver injury (Seki 2017). In this study we further compared these models.

\section{Methods}

The serum biomarker analyses were performed as previously described (Seki 2017). Briefly, 18 sixweek-old C57BL/6 mice divided into three groups $(n=6)$ were injected intraperitoneally with $100 \mu \mathrm{l}$ PBS, $200 \mu \mathrm{g}$ LPS in PBS, $5 \mu \mathrm{g}$ R848+5 mg/mouse GalN in PBS, $20 \mu \mathrm{g}$ CpG DNA+15 mg/mouse GalN in PBS.

For the antibody (Ab)-blocking analysis, 72 mice were divided into 12 groups $(n=6)$ and the following $\mathrm{Abs}$ were intraperitoneally administered: $150 \mu \mathrm{g}$ anti-Gr-1 (Ly6G, Ly6C) Ab (RB6-8C5) or

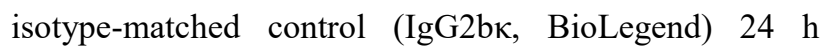
before TLRL/GalN challenge; $40 \mu \mathrm{g}$ rat anti-mouse P-selectin Ab (RB40.34) or isotype-matched control (rat IgG1 $\lambda$ Control A110.1, BD Pharmingen) $4 \mathrm{~h}$ before TLRL/GalN; and $100 \mu \mathrm{l}$ rabbit anti-thrombocyte serum (CLA31440, Cedarlane) or the control serum (CL100010) $24 \mathrm{~h}$ before TLRL/GalN. We confirmed that these 
A

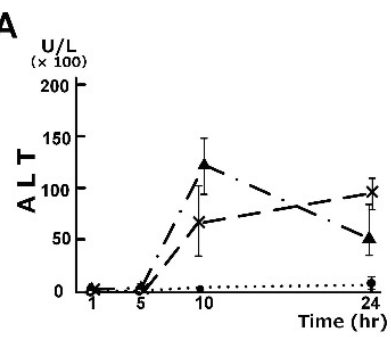

E

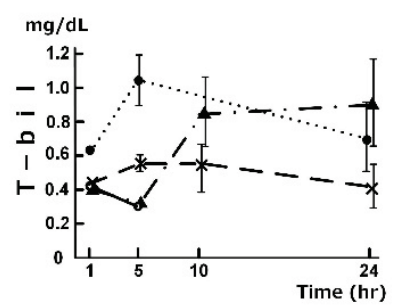

B

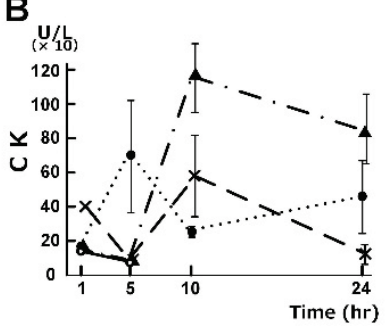

F

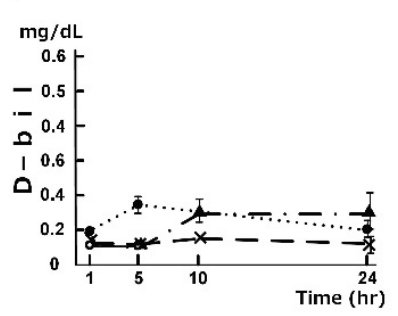

C

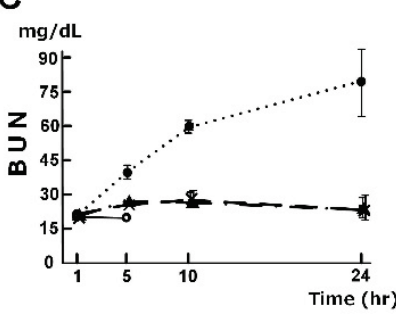

G

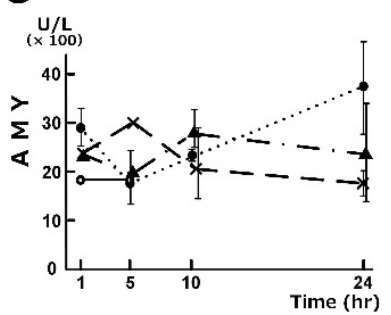

D

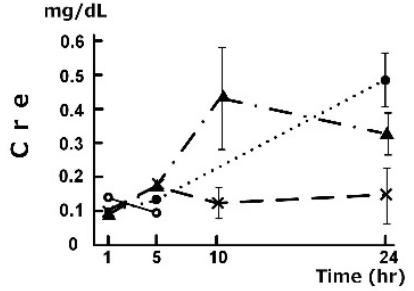

$O-O$ PBS

- LPS

- $\mathbf{A}$ R848/GalN

X- - C $\mathrm{CpG/GalN}$

Fig. 1. Serum clinical biomarker analysis. (A-G) ALT, creatine kinase (CK), blood urea nitrogen (BUN), creatinine (Cre), total bilirubin (T-bil), direct-bilirubin (D-bil) and amylase (AMY) in serum samples of PBS, LPS, CpG/GalN, and R848/GalN-injected mice were analyzed using DRI-CHEM4000 (Fujifilm) at the indicated time points. The samples of the PBS-injected mice were analyzed only for 1 and $5 \mathrm{~h}$ time points. Some error bars (SD) are hidden for clarity.

pretreatments depleted $>89 \%$ neutrophils and $>94 \%$ of platelets in blood. All experiments were performed in accordance with protocols approved by the experimental animal committee of Teikyo University.

Severe extrahepatic effects of TLR7/8 but not TLR9 agonist in galactosamine mice model

To further compare the models, we measured several serum biomarkers for the mice treated with PBS, LPS, R848/GalN, and $\mathrm{CpG} / \mathrm{GalN}$. The serum alanine aminotransferase (ALT) level showed similar increases in the R848/GalN and $\mathrm{CpG} / \mathrm{GalN}$ models (Fig. 1A). For most biomarkers other than ALT, the $\mathrm{CpG} / \mathrm{GalN}$ model did not show notable increases except for $\mathrm{CK}$, and showed lower values relative to the R848/GalN model (Fig. 1B-G). Thus, at the doses causing a similar level of liver injury, R848/GalN induced systemic responses, whereas $\mathrm{CpG} / \mathrm{GalN}$ exerted more liver-specific effects. LPS mice showed a pattern of multiple organ injury with modest liver injury.

\section{Blocking analysis supports protective roles of neutrophils}

For further comparison, we conducted Ab-blocking/depletion analyses focusing on neutrophils and platelets. The depletion of $\mathrm{Gr}-1^{+}$cells exacerbated liver injury compared to the pretreatment with the isotype-matched control in the R848/GalN model (Fig. 2B). Consistent with this, IL-6 levels were higher in the $\mathrm{Gr}-1^{+}$cell-depleted mice compared to those in the isotype-matched control (Fig. 2E). Following the IL-6 rise, IL-10 increased in $\mathrm{Gr}-1^{+}$-depleted $\mathrm{R} 848 / \mathrm{GalN}$ mice (7 h of Fig. 2F). Thus, the depletion of $\mathrm{Gr}-\mathrm{1}^{+}$cells caused aggravation of inflammation and liver injury in the R848/GalN model. Interestingly, previous studies have demonstrated the protective/anti-inflammatory effect of Gr-1 ${ }^{+}$cells (or neutrophils) (Steinshamn et al. 1995. Omert et al. 1998. Daley et al. 2005.).

Non-specific tolerance induction by antibody injection: proneness of TLR9 pathway to tolerance induction

Depletion of $\mathrm{Gr}^{+} 1^{+}$cells led to a modest aggravation of liver injury in the $\mathrm{CpG} / \mathrm{GalN}$ model (Fig. 2B) and a marked decrease in IL-6 level (Fig. 2E), lowering the IL-6/IL-10 ratio (to $<1.0$ at $7 \mathrm{~h}$ ), suggestive of the tolerance (anti-inflammatory) state at $7 \mathrm{~h}$ (Fig. 2E, F). Notably, this tolerance induction was observed even with the control $\mathrm{Ab}$, suggesting a nonspecific anti-inflammatory effect of $\mathrm{Ab}$ injection. From our experience, IL-6 levels typically reached $\sim 5 \mathrm{ng} / \mathrm{ml}$ at $7 \mathrm{~h}$ in this $\mathrm{CpG} / \mathrm{GalN}$ model without pretreatment, but it remained $<0.5 \mathrm{ng} / \mathrm{ml}$ in the $\mathrm{Ab}$-pretreated $\mathrm{CpG} / \mathrm{GalN}$ mice (either anti-Gr- $1^{+}$or isotype-matched control) (Fig. 2E, F). This non-specific tolerance-inducing effect of $\mathrm{Ab}$ was not clear in the R848/GalN model, but significant in the $\mathrm{CpG} / \mathrm{GalN}$ model based on IL-6 levels at 1 and $7 \mathrm{~h}$.

P-selectin is considered important for leukocyte recruitment and hepatocellular injury in endotoxemic anti-P-selectin $\mathrm{Ab}$ tended to aggravate liver injury relative to the isotype-matched control for both models 

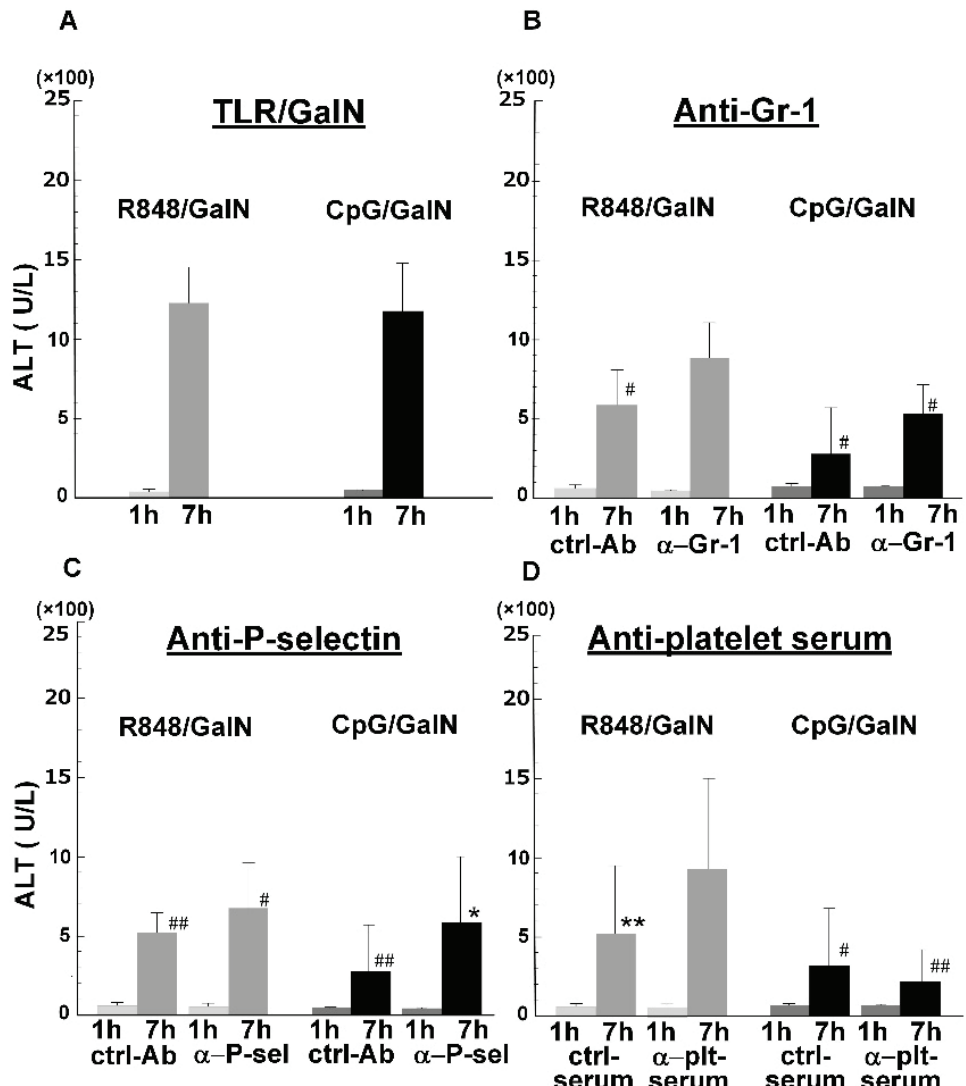
D

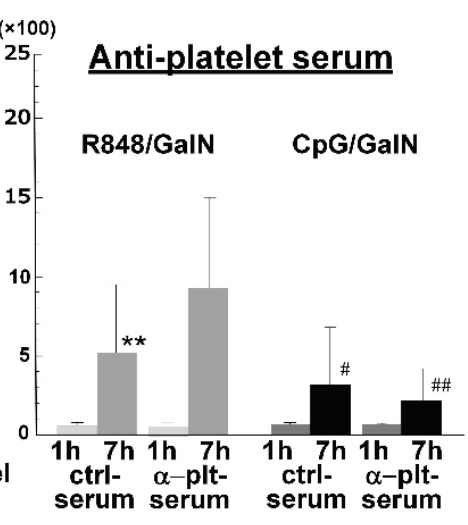

Fig. 2. Blocking/depletion analyses. The serum levels of ALT (A-D), IL-6 (E, G, I), and $\mathrm{IL}-10 \quad(\mathbf{F}, \mathbf{H}, \mathbf{J})$ in R848/GalN and CpG/GalN mice pretreated with the indicated Abs are shown. For $(A-D)$, the mean $\pm S D$ is shown. For $(\mathrm{E}-\mathrm{J})$, range (box) with median (line) \pm SD (error bar) is shown. For all analyses, differences between control $\mathrm{Ab}$ (or serum) and specific $A b$ (or serum) were insignificant. Unpretreated $(A)$ and $A b$-pretreated groups (B-D) showed differrences in ALT $\quad(* p<0.05$; $* * p<0.01 ; \quad \# p<0.005$, \#\#p<0.001). For CpG/GalN, all IL-6 data at $7 \mathrm{~h}(\mathrm{E}, \mathrm{G}, \mathrm{I})$ were lower than those from unpretreated mice, but none of IL-10 data showed such a difference $(F, H, J)$. No R848/GalN analysis showed such a difference.

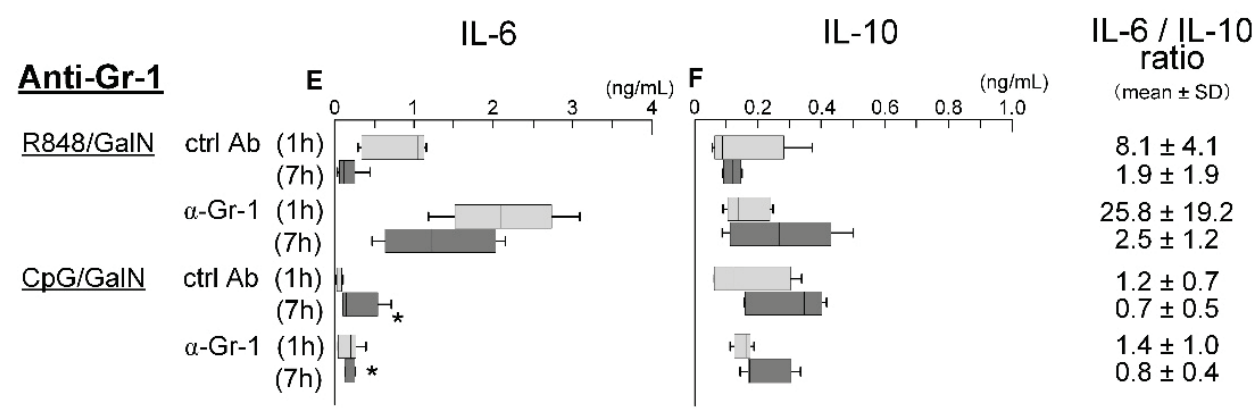

Anti-P-selectin
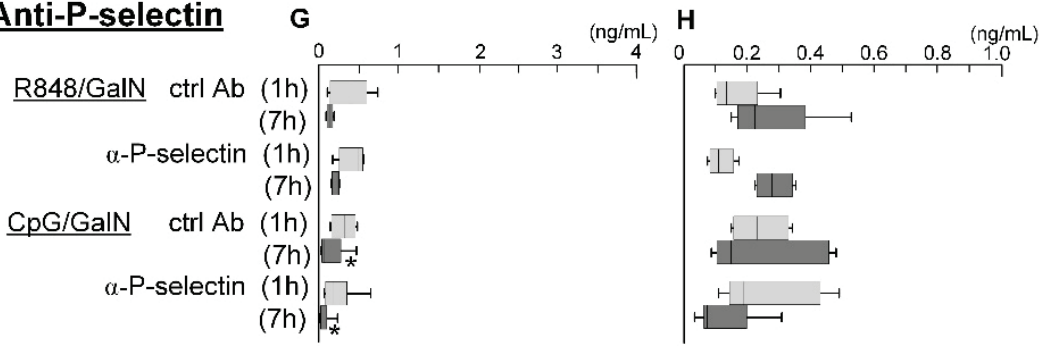

$3.0 \pm 1.5$

$0.7 \pm 0.4$

$5.3 \pm 2.9$

$0.2 \pm 0.1$

$1.4 \pm 1.0$

$0.3 \pm 0.2$

$1.3 \pm 0.7$

$0.2 \pm 0.1$

\section{Anti-platelet serum ।}
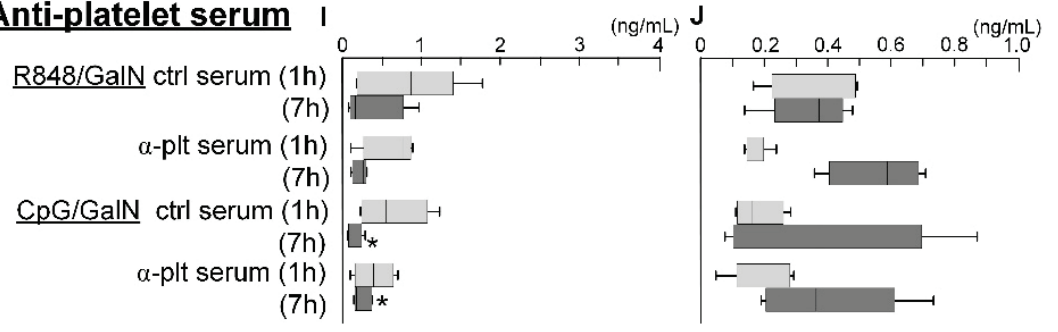

$2.6 \pm 1.1$

$1.1 \pm 0.8$

$5.1 \pm 3.9$

$0.3 \pm 0.1$

$5.4 \pm 4.8$

$1.2 \pm 1.0$

$1.7 \pm 0.4$

$1.3 \pm 1.4$ 
(Fig. 2C), suggesting a protective role of P-selectin. Cytokine analysis showed no clear effects of anti-Pselectin $\mathrm{Ab}$; however, both control and anti-P-selectin $\mathrm{Ab}$ caused low IL-6/IL-10 ratio, suggesting toleranceinducing effects (Fig. 2G, H). This effect was more pronounced for the $\mathrm{CpG} / \mathrm{GalN}$ model than for the R848/GalN model. Interestingly, without $\mathrm{Ab}$ pretreatment, the IL-6/IL-10 ratio exceeded 10 (typically, IL-6 levels reached $\sim 5 \mathrm{ng} / \mathrm{ml}$ and IL-10 $\sim 0.3$ $\mathrm{ng} / \mathrm{ml}$ ) at $7 \mathrm{~h}$ in the $\mathrm{CpG} / \mathrm{GalN}$ model (Seki and unpublished data), but with the pretreatment, the ratio remained $<1$ (Fig. 2G, H). When the effect of platelet depletion was examined, its effect on liver injury was not consistent between the models (Fig. 2D). However, for both models, the tolerance-inducing effect of both the anti-platelet and control serum was observed (Fig. $2 \mathrm{~A}, \mathrm{D}, \mathrm{I}, \mathrm{J})$. Once again, the tolerance-inducing effect based on the IL-6/IL-10 ratio was more pronounced in the $\mathrm{CpG} / \mathrm{GalN}$ model (Fig. 2I, J). The mechanism underlying this effect of "rabbit" serum is presently unknown; however, as shown in murine model analyses of intravenous immunoglobulin therapy, if the recognition of sialic acid on Fc by SIGN-R1 plays a key role (Tjon et al. 2015), this may explain this cross-species phenomenon. Overall, the Ab/serum pretreatment generally induced tolerance based on the low IL-6/IL-10 ratio, and this effect was more pronounced in the $\mathrm{CpG} / \mathrm{GalN}$ model. In the R848/GalN model, suppression by Ab/serum of IL- 6 and IL-10 was modest, with the IL-6 levels being comparable between the mice with and without pretreatment (data not shown). However, further characterization of the tolerance induction by the control $\mathrm{Ab} /$ serum in the future is necessary.

\section{Discussion}

Difference in systemic toxicity between the TLR7/8 and TLR9 agonists

The R848/GalN and CpG/GalN models showed similar levels of increase in serum levels of TNF- $\alpha$, an early inflammatory mediator (Seki 2017). Without $\mathrm{Ab}$ pretreatment, the $\mathrm{CpG} / \mathrm{GalN}$ model induced higher serum IL-6 levels $(\sim 5 \mathrm{ng} / \mathrm{ml}$ at $7 \mathrm{~h})$ relative to the $\mathrm{R} 848 / \mathrm{GalN}$ model ( $\sim 0.5 \mathrm{ng} / \mathrm{ml}$ ) (Seki 2017). Why did the $\mathrm{CpG} / \mathrm{GalN}$ model exhibit modest systemic inflammation (Fig. 1) and proneness to tolerance induction relative to the R848/GalN model (Fig. 2)? One possibility is that TLR9 signaling has a more significant impact on the liver relative to TLR7/8. Notably, TLR9 has been implicated in several liver diseases (Arrese et al. 2016, Imaeda et al. 2009, Bakker et al. 2015), whereas, to our knowledge, corresponding studies on TLR7/8 are limited. Another possibility is the limited systemic effect of the TLR9 agonist due to the protective functions of TLR9 in nonimmune cells. TLR9 has been shown to contribute to cellular protection by reducing energy substrates and activating AMP-activated protein kinase (AMPK), subsequently inducing stress tolerance (Shintani et al. 2014). The TLR9/AMPK pathway can promote autophagy, which is crucial for cell protection (Ye et al. 2018). Possibly, efficient mechanisms responsible for tolerance toward TLR9 agonists have evolved to adjust TLR9 response to endogenous ligands, including mitochondrial DNA. Of note, pretreatment with lipoteichoic acid induced tolerance in $\mathrm{CpG} / \mathrm{GalN}$ better than that in the R848/GalN model (Seki 2017).

\section{Conclusion}

This study showed that the $\mathrm{CpG} / \mathrm{GalN}$ insult induced more liver-focused injury compared to R848/GalN, which caused systemic and liver injuries, and also suggested that the tolerance induction by $\mathrm{Ab} / \mathrm{serum}$ pretreatment was more pronounced for the $\mathrm{CpG} / \mathrm{GalN}$ insult. Further analyses of the protective effects of TLR9 on various cells and induction of tolerance toward TLR9 signaling are warranted.

\section{Conflict of Interest}

There is no conflict of interest.

\section{Acknowledgements}

This work was supported by a Grant-in-Aid for Scientific Research from the Ministry of Education, Science and Culture, Japan.

\section{Abbreviation \\ GalN, D-galactosamine; TLR, toll-like receptor; $\mathrm{CpG}$, cytosine-guanosine dinucleotide; ODN, oligodeoxy- nucleotides; CK, creatine kinase; Ab, antibody}

\section{References}

ARRESE M, CABRERA D, KALERGIS AM, FELDSTEIN AE: Innate immunity and inflammation in NAFLD/NASH. Dig Dis Sci 61: 1294-1303, 2016. https://doi.org/10.1007/s10620-016-4049-X 
BAKKER PJ, SCANTLEBERY AM, BUTTER LM, CLAESSEN N, TESKE GJD, VAN DER POLL T, FLORQUIN S, LEEMANS JC: TLR9 mediates remote liver injury following severe renal ischemia reperfusion. PloS One, 10: e0137511, 2015. https://doi.org/10.1371/journal.pone.0137511

DALEY JM, REICHNER JS, MAHONEY EJ, MANFIELD L, HENRY JR WL, MASTROFRANCESCO B, ALBINA JE: Modulation of macrophage phenotype by soluble product(s) released from neutrophils. J Immunol 174 : 2265-2272, 2005. https://doi.org/10.4049/jimmunol.174.4.2265

IMAEDA AB, WATANABE A, SOHAIL MA, MAHMOOD S, MOHAMADNEJAD M, SUTTERWARA FS, FLAVELL RA, MEHAL WZ: Acetaminophen-induced hepatotoxicity in mice is dependent on Tlr9 and the Nalp3 inflammasome. J Clin Invest 119: 305-314, 2009. https://doi.org/10.1172/JCI35958

KEMELO MK, KUTINOVÁ CANOVÁ N, HORINEK A, FARGHALI H: D-galactosamine/lipopolysaccharideinduced hepatotoxicity in rats: involvement of sirtuin 1 and heme oxygenase 1. Physiol Res 66: 497-505, 2017. https://doi.org/10.33549/physiolres.933488

KLINTMAN D, LI X, THORLACIUS H: Important role of P-selectin for leukocyte recruitment, hepatocellular injury, and apoptosis in endotoxemic mice. Clin Diagn Lab Immunol 11: 56-62, 2004. https://doi.org/10.1128/CDLI.11.1.56-62.2004

OMERT L, TSUKADA K, HIERHOLZER C, LYONS VA, CARLOS TM, PEITZMAN AB, BILLIAR TR: A role of neutrophils in the down-regulation of IL-6 and CD14 following hemorrhagic shock. Shock 9: 391-396, 1998. https://doi.org/10.1097/00024382-199806000-00001

SEKI R: Toll-Like receptor ligand-induced liver injury in d-galactosamine-sensitized mice: differences between tlr7/8 and tlr9 ligands, cytokine patterns, and cross-tolerance induction by TLR2 ligand pretreatment. J Immunol Res 2017: ID 9653793, 2017. https://doi.org/10.1155/2017/9653793

SHINTANI Y, DREXLER HC, KIOKA H, TERRACCIANO CM, COPPEN SR, IMAMURA H, AKAO M, NAKAI J, WHEELER AP, HIGO S, NAKAYAMA H, TAKASHIMA S, YASHIRO K, SUZUKI K: Toll-like receptor 9 protects non-immune cells from stress by modulating mitochondrial ATP synthesis through the inhibition of SERCA2. EMBO reports 15: 438-445, 2014. https://doi.org/10.1002/embr.201337945

STEINSHAMN S, BEMELMANS MH, BUURMAN WA, WAAGE A: Granulocytopenia reduces release of soluble TNF receptor $\mathrm{p} 75$ in endotoxin-stimulated mice: a possible mechanism of enhanced TNF activity. Cytokine 7: 50-56, 1995. https://doi.org/10.1006/cyto.1995.1006

TJON AS, VAN GENT R, GEITENBEEK TB, KWEKKEBOOM J: Differences in anti-inflammatory actions of intravenous immunoglobulin between mice and men: more than meets the eye. Frontiers Immunol 6: 197, 2015. https://doi.org/10.3389/fimmu.2015.00197

YE L, FENG Z, DOYCHEVA D, MALAGUIT J, DIXON B, XU N, ZHANG JH, TANG J: CpG-ODN exerts a neuroprotective effect via the TLR9/pAMPK signaling pathway by activation of autophagy in a neonatal HIE rat model. Exp Neurol 301: 70-80, 2018. https://doi.org/10.1016/j.expneurol.2017.12.008 